\title{
Do Intangibles Influence the Market Rate of Return? \\ Panel Data Analysis of the Newconnect Market in Warsaw
}

\author{
Monika Bolek, (PhD) \\ University of Lodz, Faculty of Economics and Sociology, \\ Department of Industry Economics and Capital Market \\ Rewolucji 1905r. Street 41, 90-214, Lodz, Poland \\ Katerina Lyroudi, (PhD) \\ University of Macedonia, \\ Egnatia 156 street, 54006, Thessaloniki, Greece
}

doi: 10.19044/esj.2017.v13n1p12 $\quad$ URL:http://dx.doi.org/10.19044/esj.2017.v13n1p12

\begin{abstract}
Financial markets in most countries are changing by opening new sections of exchange for companies in early stage of development. Nowadays young companies are looking for capital from investors who are interested in financing innovative and risky projects, expecting higher rate of return. Alternative systems of trading are becoming more and more popular. This sector is growing rapidly, mostly supporting the commercialization of innovations by small and medium companies. Based on the above, we can state that innovativeness influences the rate of return of young and fast growing companies. The innovativeness is associated with the intellectual capital of a company which can be proxied and measured by its intangible assets listed on the balance sheet. Hence, we form our research question and main testable hypothesis that the level of a firm's intangible assets affects positively the rate of return on the market. We applied panel data regression analysis in various forms and we found that the cash flow is correlated positively and significantly with the rate of return while other variables like intangibles could affect the rate of return negatively and the size variable positively in a sample of small and medium sized companies. However, the model parameters are questionable since it is well known that the behavior of young companies is unpredictable.
\end{abstract}

Keywords: Rate of return, intangible assets 


\section{Introduction}

Exchange markets in most countries are developing by expanding in sections of small and medium companies with a growth potential. This trend is connected to the phases of a company's development according to some growth models (Greiner 1972, Lewis and Churchil 1987). On the other hand, young companies are looking for capital from investors who are interested in financing innovative projects. Up to now the financing of a young venture is related to the family money, seed capital funds, business "angels" and venture capital. Nowadays, the crowdfunding or alternative exchanges support the transfer of knowledge while financing the early stage of innovative product development being commercialized by young companies that can grow with money acquired on the alternative exchange. This is the reason why we have found the subject of the intangible assets in young companies tempting for further investigation and research. In Table 1 we have categorized the phases and sources of financing for a business in a different stage of development.

Table 1: THE PHASES AND SOURCES OF FINANCING

\begin{tabular}{|c|c|}
\hline 1.st Phase: Knowledge transfer, deployment & $\begin{array}{c}\text { Family money, State or University, Seed } \\
\text { capital, UE Funds, Crowdfunding }\end{array}$ \\
\hline 2.nd Phase: Commercialization & $\begin{array}{c}\text { Venture Capital, Alternative Exchange, } \\
\text { Bank, Earnings }\end{array}$ \\
\hline 3.rd Phase: Sustain development & $\begin{array}{c}\text { Exchanges, Banks, Earnings, Private } \\
\text { Equity }\end{array}$ \\
\hline
\end{tabular}

Source: own study

Alternative exchanges are becoming more and more popular since 1971, when NASDAQ was created in the USA and supported the commercialization of many companies like Microsoft, Apple, Cisco, Dell and Oracle. In Europe, London AIM was created in 1995 and is characterized by very intensive trade. Based on the EC directive MIFiD (2004/39/EC) that was introduced to the market in order to push European capital for mobilization and competitiveness with the US alternative exchange, namely the NASDAQ, there have been established alternative exchanges in various countries. This sector is growing rapidly supporting the commercialization of innovations. Investors are interested in financing this kind of ventures because of the high potential of growth and higher rate of return when such commercialization succeeds. The risk is higher of course, but the future reward is tempting, so this sector is addressed to more risk loving investors (individuals or companies).

Innovativeness should influence positively the competitiveness of a company and its cash flow, therefore it should influence the value of a company as well. We can infer that innovativeness influences the rate of return of young and fast growing companies. The innovativeness is associated with the intellectual capital of a company which can be proxied and measured by 
its intangible assets listed on the balance sheet (Hatzigagios et al. 2015). Hence, the level of the intangible assets of a firm could affect its rate of return. The rate of return is a function of fundamental factors along with the profitability ratios for evaluating a company's performance or the function of market variables according to Muhammad and Scrimgeour (2014). Our research question is whether the intangible assets affect the rate of return of a company together with other factors described in the Muhammad and Scrimgeour (2014) study. We investigate a sample of small and medium sized companies that are listed on the NewConnect Alternative Exchange in Warsaw.

New Connect Market in Warsaw in an example of the alternative trading system. This stock exchange market is addressed to small and medium sized companies and has been organized and operated by the Warsaw Stock Exchange since August 2007. NewConnect market is dedicated for young and small Polish companies that need equity capital to grow. NewConnect offers more liberal requirements, which reduce the member firms' costs. This alterative market is growing fast in Poland, with more than 500 IPOs from its opening.

Thus, our objective in this study is to investigate the relationship between a company's intangibles as a proxy of its innovativeness and the rate of return as a measure of return on investment in shares of innovative companies, since the fundamental decisions of managers influence the value of shares and the decisions of investors according to Miller and Modigliani (1961). The information about the investment in intangible assets should support investors' decisions and the demand for shares should grow or fall depending on the appraisal of such decisions. If investors consider the signal they get from investments in intangibles as a good information then the demand grows, the prices are going up and the rate of return follows up. In the opposite situation, when investors consider investments in intangibles as a bad decision, then the demand falls and the shares' prices go down causing the rate of return to decrease. Such a scenario is related to the efficiency of the market (Fama, 1970). Moreover, the direction of the market's reaction on intangibles investment is related to the society conservatism and its openness for innovativeness.

In order to achieve our objective, the paper is structured as follows: The next section discusses the fact of the rate of return being influenced by some fundamental factors and the pertinent literature. The third section describes the data, the variables used and the methodology. The fourth section depicts and analyzes the results and the last section contains a summary and concluding remarks. 


\section{Rate of Return and Fundamental Factors}

The rate of return from shares investment is a subject of many researchers that divide the problem for the fundamental and behavioral factors affecting it. Fundamental factors can be divided for macroeconomic and market. Macroeconomic factors can be linked to the APT model developed by Ross (1976). Market based factors are used in models by Fama and French (1993) with capitalization, book value to market value and beta factors. Carhart model (1997) additionally uses momentum and finally PastorStambaugh model (2003) - market liquidity. Decision of a company's management is under the interest of shareholders that are interested mainly in returns but also in innovativeness that influences the cash flow and therefore growth potential. Corporate governance is related to the relationship between managers and shareholders or stakeholders, depending on the theory taken into consideration. The goal of a company performance should be anyway related to the value maximization. Corporate governance theories and especially the stakeholder approach joins managers, investors and other parties [Jensen and Meckling 1976, Donaldson and Preston (1995)] resulting in a resource-based view of the firm [Penrose 1959].

Fundamental factors affecting the rate of return can be related to the efficiency of its operations and the growth potential. Innovative products offered by companies influence the competitiveness and the advantage related to the offer no one else can bring to the market [Cho and Pucik (2005)]. Therefore cash flow should grow, influencing the profitability of investment projects, earnings and value in the end. This should affect the decisions of investors as well as the rate of return of the company. According to Muhammad and Scrimgeour (2014) the rate of return on the investment in the shares of a specific company may be affected both by fundamental and market factors. According to the fundamental factors the equation is presented below:

$$
R=a+b_{1} R O A_{i t}+b_{2} R O E_{i t}+b_{3} E P S_{i t}+b_{4} F C F_{i t}+b_{5} \text { Size }_{i t}+e
$$

where: Size $=\lg 10 \mathrm{TA}, \mathrm{FCF}=$ Free cash flow (Net income+depreciation), EPS $=$ Earnings per share, $\mathrm{ROE}=$ Return on Equity, ROA $=$ Return on Assets, R=annual stock return.

Moreover they recognized a second model based on the capital market variables:

$$
R_{i t}=a+b_{1} P E_{i t}+b_{2} \operatorname{lnT} Q_{i t}+b_{3} M B_{i t}+b_{4} \operatorname{lnMVA} A_{i t}+b_{5} \text { CFROI }_{i t}+
$$

where: $\mathrm{PE}$ - price/earnings, TQ - Tobin's Q, MB - market value to book value, MVA - market value added, CFROI - cash flow rate of return.

Innovation is an application of knowledge to produce new knowledge [Drucker (1993)]. Based on this assumption we can look for innovations in investments in intangibles that are representing partially the $R \& D$ 
development and licenses' usage for new products. The competitiveness is related to these new products. Thereafter, if the innovations are applied efficiently, having positive net present values (NPV>0) investment projects and internal rates of return (IRR) greater than the company's cost of capital, they will lead to future growing earnings and returns. Since innovativeness influences the underlying firm's profitability according to Cho and Pucik (2004) we can add it as another independent variable to the model proposed originally by Muhammad and Scrimgeour (2014) to see how it affects the overall rate of return. This rate of return may show the investors' evaluation on those decisions in relation to innovations.

The fundamental Muhammad and Scrimgeour model has been taken into consideration since financial ratio analysis is a mean to evaluate the financial performance of a company over time and across the industrial sectors for the benefit of all the firm's stakeholders [Gallizo and Salvador (2003)]. Financial ratios allow shareholders to compare different information in a meaningful way in order to make investment decisions [Singh \& Schmidgall (2002)]. Ratio analysis provides information that summarizes the strengths and weaknesses of different forms of return, liquidity and growth perspective. After all the information is used and processed by investors in the fundamental analysis in order to make their investment decisions. The outcome is either the purchasing or the selling of the company's shares accordingly, so that the investors can achieve the specific rate of return from the price movements of the underlying shares. Jensen and Murphy (1990) and Milbourn (1996) supported that the stock price of a company, or its returns based on it, should be that company's best performance measure.

In the model presented by Muhammad and Scrimgeour (2014) there are five variables related to profitability and growth: The Return on Assets (ROA) which represents the ratio of the net income of a company during an annual period and its total assets for that year and shows the profitability of those assets. The higher those assets are, with the same level of income, the lower the firm's profitability. When investors place capital funds in a company they expect that managers to operate at the most rational way, in order to maximize that company's wealth and profits. According to Yalcin et al. (2012) the ROA is an indicator of the firm's management efficiency in their use of their company's total assets to generate earnings. Since net income is one component of the ROA, then EPS derived by net income, is also associated with the firm's assets and it should be as high as possible for the specific level of total assets. This ratio can definitely influence the rate of return of a company.

The Return on Equity (ROE) is another profitability measure, that allows the comparison of a company's profitability to other firms in the same industrial sector. Investors before deciding about investment, should compare 
the ROE of the selected company with its cost of equity capital to see if it covers the requirements, so that they will maximize their shareholders' wealth, otherwise, they reject that investment. Therefore, we can derive the research question of how the ROE affects the rate of return of a company based on the inferences of Palepu et al. (2010).

The earnings per share (EPS) is the ratio that indicates the amount of net income available for one share. This ratio is also a profitability indicator whereby according to Jordan et al. (2007) affects directly the investors' expectations about their company's earnings. Hence, based on these and following Muhammad and Scrimgeour (2014) EPS can be considered as an explanatory variable of the rate of return. According to Yalcin et al. (2012) EPS is an indicator of a company's strength, since the markets react to firms' abilities in meeting their earnings expectations. We can examine the EPS of a company along the years and determine whether it is growing, thus implying that the firm is making money or whether it is declining implying the opposite. Furthermore, Cudia and Manaligod (2011) claim that it measures a firm's economic strength in relation to its size.

Free cash flows are considered as a variable related to the profitability. The higher its value, the better the company's condition, so the assessment of this factor by investors should be positive. The higher free cash flow a company has, the cheapest its financing will be of its profitable (positive NPV) investment opportunities, since they will be financed by these funds (no debt and risk increases and no flotation costs by issuing new shares). In case there are no profitable investment opportunities to be undertaken, then the company can pay its retained earnings (free cash flows) to its owners as dividends [Muhammad and Scrimgeour (2014)].

Another explanatory variable in the model is "Size", indicating the total assets used by a company and this is an approach preferred in the literature [Richard et al. (1991), Kumar and Warne (2009)]. In advance we cannot determine a specific direction of the relationship between the firm's size and its rate of return, since in the literature there are conflicting results based on the regression model used, like in Muhammad and Scrimgeour's (2014)] study whereby it was found positive and significant in their fourth model but insignificant in their other four regression models.

Finally, we add the intangible assets variable in a logarithmic expression "InINT" to the model presented above as another independent variable to investigate and test if such information about a company influences directly the rate of return which investors may achieve on their investment in a specific company.

Companies listed on the NewConnect alternative trading system are less mature and younger - therefore smaller than the companies listed on the main market of the Warsaw Stock Exchange and the investors there are facing 
higher levels of risk but have the expectations for higher returns. These investments may be affected by the intangible assets level and this is the research question we are trying to answer in this paper. Rational expectations should suggest a positive influence of the investment in intangibles on the rate of return. Cho and Pucik (2005) found that innovativeness influence the profitability and the value of a company. If a company has an innovative product than it can influence the competitiveness' and the cash flow will rise influencing the value of a company and therefore the rate of return.

\section{Data, Variables, Testable Hypotheses and Methodology}

For the purpose of our study we use the data and ratios of companies listed on the NewConnect Alternative Exchange market in Warsaw during the period 2008 to 2013. We have disregarded all the companies for which we did not have enough data for the selected period and our final sample consists of 138 nonfinancial companies. Moreover we chose to use panel data analysis. Panel data regression models are based on panel data which is a special type of pooled data and refer to the collection of observations on many cross section units for different time periods. Panel data contain therefore both features of cross-sectional data describing collectivity in a single point in time and characteristics of time series (describing a unit's variable at different times). By combining time series of cross-section observations, panel data is more informative, has more variability, has less collinearity among the examined variables, has more degrees of freedom and is more efficient. Briefly, panel data can enrich an empirical analysis in ways that may not be possible if we use only cross-section or time series data. However, there are also some problems with panel data modeling, but they are beyond the scope of this study.

The general equation for six independent variables $\mathrm{X}_{1}$ to $\mathrm{X}_{6}$ and for the $Y$ dependent variable is expressed as follows:

$$
Y i t=\beta_{0}+\beta_{1} X 1 i t+\beta_{2} X 2 i t+\beta_{3} X 3 i t+\beta_{4} X 4 i t+\beta_{5} X 5 i t+\beta_{6} X 6 i t+u_{i t}
$$

With $i=1,2,3, \ldots, 138$ and $t=1,2, \ldots, 6$ years, where $i$ stands for the $i$ th cross-sectional unit and $t$ for the $t$ th time period.

It is assumed that there are a maximum of $N$ cross-sectional units or observations (here companies) and a maximum of $T$ time periods (here six years from 2008 to 2013). We have selected the companies so that each crosssectional unit has the same number of time series observations, creating what is called a balanced panel even though some data may be missing. The variables in our particular model are :

$\mathrm{X} 1=\mathrm{ROA}=$ the return on assets

$\mathrm{X} 2=\mathrm{ROE}=$ the return on equity

$\mathrm{X} 3=\mathrm{EPS}=$ the earnings per share 
$\mathrm{X} 4=\operatorname{lnFCF}=$ the natural logarithm of the free cash flows

$\mathrm{X} 5=$ Size $=$ the $\log _{10}$ of Total Assets

$\mathrm{X} 6=\ln I \mathrm{~N}=$ the natural logarithm of the intangible assets

$\mathrm{Y}=\mathrm{R}=$ the rate of return

We do transformations of our variables to treat heteroscedasticity and nonnormality.

In the first model, we examine the results of a pooled regression on all the available observations (disregarding the space and time dimensions). With such assumptions we can stack the six observations for each company from 2008 to 2013, one on top of the other, getting $6 \times 138$ companies $=828$ observations. The model is given below:

$$
\begin{aligned}
& R=a+b_{1} R O A_{i t}+b_{2} R O E_{i t}+b_{3} E P S_{i t}+b_{4} \operatorname{lnFCF} F_{i t}+b_{5} \text { Size }_{i t}+ \\
& b_{6} I N_{i t}+e_{i t}
\end{aligned}
$$

We assume that companies' features are different, which is a reasonable assumption in most analyses. This means that the intercepts cannot be the same for each company in the sample, so we can assume that the intercept varies for each company, considering the "individuality" of each company (each cross-sectional unit), but we keep the assumption of constant slope coefficients across firms and time. This regression model is called Fixed Effects (regression) Model or FEM and can be expressed as follows:

$$
Y i t=\beta_{0 i}+\beta_{1} X 1 i t+\beta_{2} X 2 i t+\beta_{3} X 3 i t+\beta_{4} X 4 i t+\beta_{5} X 5 i t+\beta_{6} X 6 i t+u_{i t}
$$

With $i=1,2,3, \ldots, 138$ and $t=1,2, \ldots, 6$ years, where $i$ stands for the $i$ th cross-sectional unit and $t$ for the $t$ th time period.

Here the subscript (i) on the intercept term $\left(\beta_{0} i\right)$, means that the intercept of the $\mathrm{i}$ firm may be different (due to special features of each company), but they do not vary over time (they are time invariant). The $X_{\mathrm{s}}$ and $Y$ are equal to the variables described in Equation (1).

When the fixed effect intercept varies between firms we include dummy variables called the differential intercept dummies and we have the following model, called the Least Squares Dummy Variable model (LSDV):

Yit $=\alpha_{1}+\alpha_{2} \mathrm{D}_{2 \mathrm{i}}+\ldots+\alpha_{138} \mathrm{D}_{137 \mathrm{i}}+\beta_{1} X 1 i t++\beta_{2} X 2 i t+\beta_{3} X 3 i t+\beta_{4} X 4 i t+$ $\beta_{5} X 5 i t+\beta_{6} X 6 i t+u_{i t}$

Since we have 138 companies, we have used only 137 dummies to avoid falling into the dummy-variable trap (i.e., the situation of perfect collinearity). Here there is no dummy for company 1. In other words, $\alpha 1$ represents the intercept of company 1 , and $\alpha_{2}, \alpha_{3}, \ldots$ and $\alpha_{137}$, the differential intercept coefficients, telling by how much the intercepts of companies 2 to 138 differ from the intercept of company 1. 
Just as we used the dummy variables to account for individual (company) effect, we can allow for time effect as the $Y$ function shifts over time because of factors such as technological changes, changes in government regulatory and/or tax policies, and external effects such as wars or other conflicts. Such time effects can be easily accounted for, if we introduce time dummies, one for each year. Since we have data for 6 years, from 2008 to 2013, we can introduce 5 time dummies, and write the model as:

$$
\begin{aligned}
& \text { Yit }=\lambda 0+\lambda 1 \text { Dum08 }+\lambda 2 \text { Dum09+ } \cdots+\lambda 6 \text { Dum } 13++\beta_{1} X 1 i t+\beta 2 X 2 i t+ \\
& \beta 3 X 3 i t+\beta_{4} X 4 i t+\beta_{5} X 5 i t+\beta_{6} X 6 i t+\text { uit }
\end{aligned}
$$

where Dum08 takes a value of 1 for observation in year 2008 and 0 otherwise, etc. We are treating the year 2013 as the base year, whose intercept value is given by $\lambda 0$.

On the basis of the restricted $F$ test, if this increment is not significant, it probably suggests that the year or time effect is not significant. This might suggest that perhaps the rate of return function has not changed much over time. Some of the individual company effects could be statistically significant, but the individual year effects may not. If this is the case, then we can infer that our model is mis-specified in the sense that we have not taken into account both individual and time effects together. We can state that all coefficients vary across individuals and here we assume that the intercepts and the slope coefficients are different for all individual, or cross-section, units. We introduced the individual dummies in an additive manner. Although straightforward to apply, fixed effects, or LSDV, modeling can be expensive in terms of degrees of freedom if we have several cross-sectional units. If the dummy variables do in fact represent a lack of knowledge about the (true) model, then expressing this ignorance through the disturbance term $u_{i t}$ we get the following equation:

$$
\text { Yit }=\beta_{0 i}+\beta_{1} X 1 i t+\beta_{2} X 2 i t+\beta_{3} X 3 i t+\beta_{4} X 4 i t+\beta_{5} X 5 i t+\beta_{6} X 6 i t+\varepsilon i+u_{i t}
$$

Instead of treating $\beta_{0 i}$ as fixed, we assume that it is a random variable with a mean value of $\beta_{0}$ (no subscript $i$ here), and the intercept value for an individual company can be expressed as:

$$
\beta_{0 i}=\beta_{0}+\varepsilon_{i} \quad \text {, where } i=1,2, \ldots, N
$$

where $\varepsilon_{i}$ is a random error term with a mean value of zero and variance of $\sigma^{2}$, $\varepsilon . \varepsilon_{i}$, which is the cross-section, or individual-specific, error component, and $u_{i t}$, which is the combined time series and cross-section error component. The term error components model derives its name because the composite error term $w_{i t}$ consists of two (or more) error components. 
There are some estimation techniques that try to overcome one or more of these problems. The two most prominent ones are: (1) the fixed effects model (FEM) and (2) the random effects model (REM) or error components model (ECM), whereby the Hausman test can be applied to help us decide between the appropriateness of the FEM or the ECM. In the FEM the intercept in the regression model is allowed to differ among individuals in recognition of the fact that each individual or cross-sectional unit may have some special characteristics of its own, so it has its own (fixed) intercept value, in all $N$ such values for $N$ cross-sectional units. In order to account for the different intercepts, we can use dummy variables. Then that FEM with dummy variables is known as the least-squares dummy variable (LSDV) model and is appropriate in situations where the individual specific intercept may be correlated with one or more regressors. A disadvantage of the LSDV is that it consumes a lot of degrees of freedom when the number of cross-sectional units, $N$, is very large, since we will have to use $N$ dummies.

In the ECM, on the other hand, the intercept $\beta_{1}$ of an individual unit represents the mean value of all the (cross-sectional) intercepts and the error component $\varepsilon_{i}$ represents the (random) deviation of individual intercept from this mean value. However, it should be noted that $\varepsilon_{i}$ is not directly observable and is known as an unobservable, or latent variable. One advantage of the ECM over the FEM is that we do not have to face the problem of many degrees of freedom, as we do not have to estimate $N$ cross-sectional intercepts. We only need to estimate the mean value of the intercept and its variance. The ECM is appropriate in situations where the (random) intercept of each crosssectional unit is uncorrelated with the regressors.

When the explanatory variables $\mathrm{x}_{\mathrm{i}, \mathrm{t}}$ are uncorrelated with the disrupting term $v_{i, t}$ for all the periods they are called strictly exogenous. Assuming strict exogenity, the Hausman test can be used to examine whether the unobservable heterogeneity is associated with the independent variables. If it is not correlated, then the estimator of the random effects is effective. On the other hand, if it is correlated, then the estimator of the fixed effects model is effective, while the estimator of random effects is not. So, when the value of the Hausman statistic is large, the model of the random effects is discarded in favor of the model of fixed effects. According to the null hypothesis, we accept that the random effects estimator is right. If the standard Hausman test rejects the null hypothesis that the conditional mean of the disturbances given the regressors is zero or that the random affects are uncorrelated with the explanatory variables, then we have to apply the fixed effect estimator. Otherwise, in the case in which we cannot reject the null hypothesis, we apply the random effect estimator. 


\section{Results and Analysis}

First we have run a Pearson correlation analysis of all the variables included in our study. The correlation analysis coefficients between the rate of return (R) and the other variables are presented in Table 2. As we observe from Table 2, only the variable of free cash flows is related positively and significantly with the rate of return (cor. coeff. Equal to 0,13 and t-statistic equal to 2,51), in a log form. This result implies that as the free cash flows in the company increase, so does the rate of return and the reverse.

Table 2. Pearson Correlation analysis of variables

\begin{tabular}{|c|c|c|c|c|c|c|}
\hline Variable & EPS & FCF & IN & Size & ROA & ROE \\
\hline $\begin{array}{c}\text { Correlation } \\
\text { coefficient with } \\
\text { R }\end{array}$ & 0,01 & $0,13^{*}$ & 0,00 & 0,05 & 0,04 & 0,01 \\
\hline t-Statistic & 0,31 & 2,51 & 0,04 & 1,38 & 1,10 & 0,15 \\
\hline p-value & 0,76 & 0,01 & 0,96 & 0,17 & 0,27 & 0,88 \\
\hline Observations & 826,00 & 383,00 & 565,00 & 828,00 & 791,00 & 742,00 \\
\hline
\end{tabular}

* Statistical significance at the $5 \%$ level.

** Statistical significance at the $10 \%$ level.

Source: own study

The Panel data analysis is done based on the Pooled Least Squares Method that will be used with cross section and period effects notification. Moreover both cross-section and period effects might be fixed or random. The first analysis is so called naïve analysis. The results are shown in Tables 3 and 4.

Table 3. Pooled Least Squares model coefficients

\begin{tabular}{|c|c|c|c|c|}
\hline Variable & Coefficient & Standard Error & t-statistic & p-value \\
\hline & & & & \\
\hline ROE & 0,63 & 6,29 & 0,10 & 0,92 \\
\hline ROA & $-3,59$ & 13,39 & $-0,27$ & 0,79 \\
\hline SIZE & 0,67 & 1,63 & 0,41 & 0,68 \\
\hline EPS & 0,53 & 1,04 & 0,51 & 0,61 \\
\hline FCF & 0,35 & 0,98 & 0,35 & 0,72 \\
\hline IN ${ }^{*}$ & $-0,75$ & 0,35 & $-2,17$ & 0,03 \\
\hline
\end{tabular}

* Statistical significance at the 5\% level.** Statistical significance at the $10 \%$ level.

Source: own study

Due to the results of the naïve analysis only intangible assets affect covertly the rate of return. In the next step we will estimate model parameters. 
Table 4. Pooled Least Squares model estimations

\begin{tabular}{|c|c|c|c|}
\hline R-squared & 0,03 & Mean dependent var & 1,15 \\
\hline $\begin{array}{c}\text { Adjusted } \\
\text { R-squared }\end{array}$ & 0,01 & SD dependent var & 13,55 \\
\hline SE of regression & 13,49 & Akaike info criterion & 8,07 \\
\hline $\begin{array}{c}\text { Sum of squared } \\
\text { resid. }\end{array}$ & 45339,62 & Schwarz criterion & 8,15 \\
\hline Log likelihood & $-1022,37$ & Hannan-Quinn crit. & 8,10 \\
\hline Durbin-Watson stst & 0,21 & & \\
\hline
\end{tabular}

Source: own study

Pooled Least Squares model estimations are poor showing very low adjusted R-squared. Since the cross-section and period effects may influence the results further analysis has been done and the results are provided below. We start with cross-section fixed effect analysis that is presented in Tables 5 and 6.

Table 5. Pooled Least Squares model coefficients with Cross-section fixed effect analysis

\begin{tabular}{|c|c|c|c|c|}
\hline Variable & Coefficient & Standard Error & t-statistic & p-value \\
\hline C & 0,37 & 12,16 & 0,03 & 0,98 \\
\hline ROE & 2,88 & 4,36 & 0,66 & 0,51 \\
\hline ROA & $-5,72$ & 10,06 & $-0,57$ & 0,57 \\
\hline SIZE & 0,10 & 3,25 & 0,03 & 0,97 \\
\hline EPS & 0,33 & 0,71 & 0,47 & 0,64 \\
\hline FCF & 0,22 & 0,65 & 0,34 & 0,73 \\
\hline IN & $-0,23$ & 0,31 & $-0,75$ & 0,46 \\
\hline
\end{tabular}

Source: own study

None of the parameters is statistically significant when the crosssection fixed effects are the basis of the analysis. Model coefficients with cross-section effect model estimations are presented below.

Table 6. Pooled Least Squares model coefficients with cross-section effect model estimations

\begin{tabular}{|c|c|c|c|}
\hline R-squared & 0,94 & Mean dependent var & 1,15 \\
\hline $\begin{array}{c}\text { Adjusted } \\
\text { R-squared }\end{array}$ & 0,88 & SD dependent var & 13,55 \\
\hline SE of regression & 4,74 & Akaike info criterion & 6,25 \\
\hline Sum of squared resid & 2623,82 & Schwarz criterion & 8,17 \\
\hline Log likelihood & $-659,05$ & Hannan-Quinn crit. & 7,02 \\
\hline F-statistic & 14,32 & Durbin-Watson stst & 3,41 \\
\hline Prob (F-statistic) & 0,00 & & \\
\hline
\end{tabular}

Source: own study

None of variables is significant but the pooled Least Squares model coefficients with cross-section effect model estimations bring adjusted $\mathrm{r}$ squared at 0,88 with prod F-stat $=0,00$ but we cannon conclude basing on this model results. Period fixed effects will be subject of the further analysis and the results are presented in Tables 7 and 8 . 
Table 7. Pooled Least Squares model coefficients with period fixed effect analysis

\begin{tabular}{|c|c|c|c|c|}
\hline Variable & Coefficient & Standard Error & t-statistic & p-value \\
\hline C & $-15,33$ & 7,13 & $-2,15$ & 0,03 \\
\hline ROE & 1,51 & 6,31 & 0,24 & 0,81 \\
\hline ROA & 1,94 & 13,74 & 0,14 & 0,89 \\
\hline SIZE* & 4,94 & 2,57 & 1,92 & 0,06 \\
\hline EPS & 0,01 & 1,08 & 0,01 & 0,99 \\
\hline FCF & $-0,22$ & 1,03 & $-0,22$ & 0,83 \\
\hline IN & $-0,43$ & 0,37 & $-1,16$ & 0,25 \\
\hline
\end{tabular}

* Statistical significance at the 5\% level.

** Statistical significance at the $10 \%$ level.

Source: own study

Based on the results presented in Table 7 we can see that size affects the rate of return when period fixed effects are taken into consideration.

Table 8. Pooled Least Squares model coefficients with fixed period effect model

estimations

\begin{tabular}{|c|c|c|c|}
\hline R-squared & 0,05 & Mean dependent var & 1,15 \\
\hline $\begin{array}{c}\text { Adjusted } \\
\text { R-squared }\end{array}$ & 0,01 & SD dependent var & 13,55 \\
\hline SE of regression & 13,50 & $\begin{array}{c}\text { Akaike info } \\
\text { criterion }\end{array}$ & 8,09 \\
\hline $\begin{array}{c}\text { Sum of squared } \\
\text { resid }\end{array}$ & 44258,26 & Schwarz criterion & 8,26 \\
\hline Log likelihood & $-1019,29$ & Hannan-Quinn crit. & 8,16 \\
\hline F-statistic & 1,18 & Durbin-Watson stst & 0,23 \\
\hline Prob (F-statistic) & 0,30 & & \\
\hline
\end{tabular}

Source: own study

The model R-squared is very low with only one variable being statistically significant. In the next step random cross-section effect analysis has been done and the results are presented below in Tables 9 and 10 .

Table 9. Pooled EG Least Squares model coefficients with random cross-section effect analysis

\begin{tabular}{|c|c|c|c|c|}
\hline Variable & Coefficient & Standard Error & t-statistic & p-value \\
\hline C & $-18,55$ & 7,10 & $-2,61$ & 0,01 \\
\hline ROE & 1,21 & 3,82 & 0,32 & 0,75 \\
\hline ROA & $-1,45$ & 9,07 & $-0,16$ & 0,87 \\
\hline SIZE* & 5,37 & 2,00 & 2,69 & 0.01 \\
\hline EPS & 0,38 & 0,63 & 0,59 & 0,55 \\
\hline FCF & 0,15 & 0,59 & 0,25 & 0,80 \\
\hline IN* & $-0,51$ & 0,26 & $-1,95$ & 0,05 \\
\hline
\end{tabular}

* Statistical significance at the $5 \%$ level.

** Statistical significance at the $10 \%$ level.

Source: own study 
Based on the results presented in Table 9 we can see, that size and intangibles are the only factors of our model affecting the rate of return significantly on the $5 \%$ statistical significance level.

Table 10. Pooled EG Least Squares model coefficients with random cross-section effect model estimations

\begin{tabular}{|c|c|c|c|}
\hline R-squared & 0,04 & Mean dependent var & 0,36 \\
\hline $\begin{array}{c}\text { Adjusted } \\
\text { R-squared }\end{array}$ & 0,02 & SD dependent var & 5,56 \\
\hline SE of regression & 5,50 & Sum squared resid & 7514,02 \\
\hline F-statistic & 1,82 & Durbin-Watson stst & 1,22 \\
\hline Prob (F-statistic) & 0,10 & & \\
\hline
\end{tabular}

Source: own study

Based on Table 9, in this model specification we can see that rate of return is influenced significantly by the variables of size (coefficient equal to 5,37 and t-statistic equal to 2,69) positively at the 5\% level and intangibles (coefficient equal to $-0,51$ and t-statistic equal to -1,95) negatively at the $10 \%$ level. The bigger the company, the higher the rate of return. However, the intangibles influence the rate of return negatively. The higher the intangibles the lower the rate of return. This paradox may be related to the stage of development of the companies and since they are young and try to commercialize their products, they very often fail. The innovative products have a high inherent amount of risk and the commercialization process is quite complicated and needs a special knowledge in this field. In other words, we suggest that in innovative companies as the level of intangible assets increase, their rate of return may decreases. The model testing is unacceptable since the $\mathrm{R}$-squared is very low with prob $\mathrm{F}-$ stat. $=0,10$.

We run Housman tests to recognize random effects affecting the results of the model. In our case we can test cross-section random effect only since the period random effects analysis was not run. The null hypothesis states that there is no misspecification (assuming random effects) affecting the model. If the $\mathrm{p}$-value is less than 0,05 we have to reject the null hypothesis.

Table 11. Housman Cross-section random effects test

\begin{tabular}{|c|c|c|c|}
\hline Test Summary & Chi-Sq Statistic & Chi-sq, $\mathrm{d}, \mathrm{f}$ & $\mathrm{p}$-value \\
\hline Cross-section random & 7,25 & 6,00 & 0,30 \\
\hline
\end{tabular}

$$
\text { Source: own study }
$$

The results show that we cannot reject the null hypothesis and we can conclude that there are random effects influencing the results of the model. The pattern of growth of small and medium companies is not fixed and random effects are determining the growth according to Lotti at all. (2003). The Redundant Fixed Effects Test tests for the existence of period fixed effects with null hypothesis that there are not fixed effects. If p-value $<0,05$ than we 
have to reject the null hypothesis. The results for the model are presented in Tables 11 and 12 .

Table 12. Redundant Cross-section fixed effects tests

\begin{tabular}{|c|c|c|c|}
\hline Effects Test & Statistic & $\mathrm{d}, \mathrm{f}$ & $\mathrm{p}$-value \\
\hline Cross-section F & 14,26 & $-131,12$ & 0,00 \\
\hline Cross-section Chi-sq & 721,98 & 131 & 0,00 \\
\hline
\end{tabular}

Source: own study

Table 13. Period fixed effects test

\begin{tabular}{|c|c|c|c|}
\hline Effects Test & Statistic & $\mathrm{d}, \mathrm{f}$ & p-value \\
\hline Cross-section F & 0,29 & $-5,24$ & 0,92 \\
\hline Cross-section Chi-sq & 1,50 & 5,00 & 0,91 \\
\hline
\end{tabular}

Source: own study

Redundant cross-section fixed effects tests show p-value to be less than 0,05 and therefore we have to reject the hypothesis that there are no fixed effects - it means, that there are fixed cross-section effects in the model we analyzed. Moreover the period fixed effects have been analyzed. In our case we cannot accept the null hypothesis related to the period fixed effects, since the ( $\mathrm{p}$-value $>0,05$ ) as it is observed in Table 12 and we can state that there are no fixed period effects. The economic crisis and the various events occurring in specific years according to our study do not affect the results, but are rather influenced by specific companies which is proved by the cross-section fixed effects existence.

\section{Conclusion}

Our results show that when we analyze the fundamental factors influencing the rate of return of small and medium companies listed on the alternative exchange NewConnect - the cash flow and moreover size and the intangible assets of the underlying company may affect it. The panel data model results are very poor that we can have only suspicions about the relationships. The results are proving that predictability of early stage companies is very low and therefore we cannot apply any model to the patterns of development since they do not exist.

We have analyzed the market of the so called "take-off" companies looking for capital on the alternative exchange for the companies' development. According the results we can expect that investors may treat the size of a firm as a positive indicator. This relation is joined to the theories of growth and the fact that larger size implies the potential or proves the existence of development. As a consequence it makes investors believe that "take-off" is successful (when assets are growing). The second factor that may affect the rate of return is intangible assets. Investors may not consider intangibles and 
therefore innovation as a positive return influencing factor. We can infer that Polish investors may be conservative in the case of new technologies and R\&D after investing in some unsuccessful commercialization projects.

As it was shown from our results the influence of innovation as represented by the intangible assets of a company, on that company's rate of return is negative. In other words, the more intangibles in a firm, the lower its rate of return. One reason could be that investors may not be able to deduce the growth potential of such companies. Or it could be the investors' interpretation of innovation, or their conservatism regarding the increased risk that innovations carry inherently. The examination of risk's influence on the rate of return is beyond the scope of this paper but is a subject for future research expanding the present study. This is not the only case in history where the society is not interested in financing innovations, as for instance in the Denmark and Novo Industri insulin case (Porter and Enright, 1994).

In contrast to our hypotheses, the other fundamental factors we used were not statistically significant: The ROE, ROA and the EPS are not affecting significantly the rate of return in any of the models we analyzed. This result is the opposite of the one found by the Muhammad and Scrimgeour (2014) study regarding the ROA and the EPS variables which had a significant positive impact on the rate of return. Housman test suggests that there are random effects affecting the results and there is no misspecification of the model. Redundant cross-section fixed effects tests suggest that they influence the results. If it is so, we can speculate about the investors' conservative behavior in Poland and the market consideration as not being successful in innovation commercialization. Only the variable of size may have a positive impact on the rate of return, in contrast to findings of Muhammad and Scrimgeour (2014) for the Australian market.

Future research in order to get more insights should examine the same hypotheses for a sample of developed European economies and a sample of more transition economies in Europe to see whether this conservatism of the Polish investors (a negative intangible assets effect on the rate of return) is a common trait in these latter economies or it appears in the developed economies as well. Another direction for future research is the investigation of these relations including also the variable of systematic risk measured by the beta coefficient.

\section{References:}

1. Carhart, M. M. (1997). On Persistence in Mutual Fund Performance. The Journal of Finance, 52 (1), 57-82.

2. Cho, H. J., \& Pucik, V. (2005). Relationship Between Innovativeness, Quality, Growth, Profitability, and Market Value. Strategic Management Journal, 26(6), 555-575. 
3. Cudia, C. P., \& Manaligod, G. T. (2011). EPS as a Measure of Intercompany Performance:Philippine Evidence Journal of International Business Research, 10(1), 79-90.

4. Donaldson, T., \& Preston, L. E. (1995). The Stakeholder Theory of the Corporation: Concepts, Evidence, and Implications. Academy of Management Review, 20(1), 65-91.

5. Drucker, P. F. (1993). Managing for the Future. Routledge.

6. Fama, E. F. (1970). Efficient Capital Markets: A Review of Theory and Empirical Work. The Journal of Finance, 25(2), 383-417.

7. Fama, E. F., \& French, K. R. (1993). Common Risk Factors in the Returns on Stocks and Bonds. Journal of Financial Economics, 33(1), 3-56.

8. Gallizo, J. L., \& Salvador, M. (2003). Understanding the Behavior of Financial Ratios: The Adjustment Process. Journal of Economics and Business, 55(3), 267-283. http://dx.doi.org/10.1016/S0148$\underline{6195(03) 00022-5}$

9. Hatzigagios, T., Lyroudi, K., \& Bolek, M. (2015). Intangible Assets from a Legal and a Finance Perspective: The Case of Polish Companies. Available at SSRN. https://ssrn.com/abstract=2668477

10. or http://dx.doi.org/10.2139/ssrn.2668477

11. Greiner, L. E. (1972). Evolution and Revolution as Organizations Grow. Harvard Business Review, July-August 1972, 37-46

12. Greiner, L. E. (1998). Evolution and Revolution as Organizations Grow, Harvard Business Review, May-June 1998, reprint, 1-12.

13. Jensen, M. and Murphy, K., (1990), Performance Pay and TopManagement Incentives, Journal of Political Economy, vol. 98, no 2 (April), 225-262.

14. Jensen, M. C., Meckling, W. H. (1976). Theory of the Firm: Managerial Behavior, Agency Costs and Ownership Structure. Journal of Financial Economics, 3(4), 305-360.

15. Jordan, C. E., Clark, S. J., \& Smith, W. R. (2007). Should Earnings per share (EPS) Be Taughtas a Means of Comparing Intercompany Performance? The Journal of Education for Business, 82(6), 343-348. http://dx.doi.org/10.3200/JOEB.82.6.343-348.

16. Kumar, S., \& Warne, D. (2009). Parametric Determinants of PriceEarnings Ratio in Indian Capital Markets. The IUP Journal of Applied Finance, 15(9), 63-82.

17. Lewis, V. L., Churchill, N. C. (1987). The Five Stages of Small Business Growth, Witryna: http://papers.ssrn.com/sol3/papers.cfm?abstract_id=1504517.

18. Milbourn, T. (1996), The Executive Compensation Puzzle: Theory and Evidence, IFA Working Paper no 235, London Business School. 
19. Miller, M. H., \& Modigliani, F. (1961). Dividend Policy, Growth, and the Valuation of Shares. The Journal of Business, 34(4), 411-433.

20. Muhammad, N. and Scrimgeour, F. (2014). Stock Returns and Fundamentals in the Australian Market. Asian Journal of Finance and Accounting, ISSN 1946-052X, vol. 6 (1), 271-290.

21. Palepu, K. G., Healy, P. M., Bernard, V. L., Wright, S., Bradbury, M., \& Lee, P. (2010).Business Analysis \& Valuation: Using Financial Statements (4ed.). Mason: South-Western Cengage Learning.

22. Pastor, L., \& Stambaugh, R. F. (2003). Liquidity Risk and Price Discovery. Journal of Political Economy, 111(3), 642-685.

23. Penrose, E.T. (1959). The Theory of the Growth of the Firm, Blackwell, Oxford and New York: John Wiley.

24. Porter, M E., and Michael J. E. "(1994) Novo Industri." Harvard Business School Case 389-148, April 1989. (Revised January 1994.)

25. Richard, L.C. Lewis, P. F. and Michael, J.S. (1991). Factors Affecting Price Earnings Ratios and Market Values of Japaneses Firms. Financial Management, 20 (4), 68-79.

26. Ross, S. A. (1976). The Arbitrage Theory of Ccapital Asset Pricing. Journal of Economic Theory, 13(3), 341-360.

27. Singh, A., \& Schmidgall, R. S. (2002). Analysis of Financial Ratios Commonly Used by US Lodging Financial Executives. Journal of Retail \& Leisure Property, 2(3), 201-213.

28. http://dx.doi.org/10.1057/palgrave.rlp.5090210

29. Yalcin, N., Bayrakdaroglu, A., \& Kahraman, C. (2012). Application of Fuzzy Multi-criteria Decision Making Methods for Financial Performance Evaluation of Turkish Manufacturing Industries. Expert Systems with Applications, 39(1), 350-364. http://dx.doi.org/10.1016/j.eswa.2011.07.024 